\title{
Selective Enhancement of P-Type Calcium Currents by Isoproterenol in the Rat Amygdala
}

\author{
Chiung-Chun Huang, Su-Jane Wang, and Po-Wu Gean \\ Department of Pharmacology, College of Medicine, National Cheng-Kung University, Tainan City, Taiwan 70101
}

\begin{abstract}
We investigated activation of $\beta$-adrenergic receptor-adenylyl cyclase-cAMP cascade on the whole-cell voltage-dependent $\mathrm{Ca}^{2+}$ currents $\left(I_{\mathrm{Ca}}\right)$ in acutely isolated rat basolateral amygdala neurons. Application of $\beta$-receptor agonist isoproterenol (Iso) caused a long-term enhancement of $I_{\mathrm{Ca}}$. The effect of Iso was blocked by concurrent application of $\beta$-receptor antagonist propranolol. However, delayed application of propranolol after the $I_{\mathrm{Ca}}$ enhancement did not affect Iso-induced potentiation, suggesting that the sustained effect was not caused by a slow washout of Iso. Nimodipine and $\omega$-conotoxin-GVIA reduced the $I_{\text {Ca }}$ by $\sim 35$ and $\sim 29 \%$, respectively, without reducing enhancement of $I_{\mathrm{Ca}}$ by Iso significantly. The modulation appeared to involve P-type current, because the enhancement was abol-
\end{abstract}

Protein phosphorylation is a widespread mechanism for signal transduction in the CNS (Nestler and Greengard, 1984; Levitan, 1985). The actions of presynaptic protein kinases in the modulation of transmitter release are particularly important and are probably involved in short- and long-term synaptic plasticity (Byrne and Kandel, 1996). In mammalian hippocampus, a role for cAMP and cAMP-dependent protein kinase (PKA) in the induction of long-term potentiation (LTP), which is a likely mechanism for learning and memory (Bliss and Lomo, 1973; Bliss and Collingridge, 1993) at the mossy fiber $\rightarrow$ CA3 synapses has been demonstrated (Huang et al., 1994; Weisskopf et al., 1994). Mossy fiber LTP required a rise in presynaptic $\mathrm{Ca}^{2+}$ that activated calmodulin-sensitive adenylyl cyclase and the consequent rise in cAMP, resulting in a long-lasting enhancement of glutamate release. In contrast, in the Schaffer collateral $\rightarrow$ CA1 synapses, activation of $\beta$-adrenergic receptor and adenylyl cyclase increased transmitter release in a reversible manner (Chavez-Noriega and Stevens, 1992; Gereau and Conn, 1994). In addition, cAMP does not act presynaptically to evoke LTP but instead functions as a gate by regulating the activity of phosphoprotein phosphatases postsynaptically (Blitzer et al., 1995; Thomas et al., 1996).

In the amygdala, we have previously shown that activation of $\beta$-adrenergic receptor by isoproterenol (Iso) caused a long-term enhancement of EPSP that was accompanied by a decrease in paired pulse facilitation (Huang et al., 1996). The sensitivity of postsynaptic neurons to the glutamate receptor agonist was unchanged, consistent with a presynaptic site of action. Furthermore, the effect of Iso was prevented by low concentrations of

\footnotetext{
Received Sept. 22, 1997; revised Dec. 5, 1997; accepted Jan. 6, 1998.

This study was supported by the National Science Council of Taiwan Grant NSC86-2314-B006-002 M10. We thank Drs. M. D. Lai and T. H. Leu for their insightful comments on this manuscript.

Correspondence should be addressed to Dr. Po-Wu Gean at the above address.

Copyright (C) 1998 Society for Neuroscience $0270-6474 / 98 / 162276-07 \$ 05.00 / 0$
}

ished after pretreatment with $\omega$-agatoxin-IVA. Forskolin, an adenylyl cyclase activator, mimicked the action of Iso in enhancing $I_{\mathrm{Ca}}$, and this effect was blocked by an inhibitor of cAMP cascade, indicating a cAMP-dependent mechanism. Iso also induced a long-term potentiation (LTP) of synaptic transmission, which could be prevented by $\mathrm{P}$-type $\mathrm{Ca}^{2+}$ channel blockers. These results suggest that $\mathrm{P}$-type $\mathrm{Ca}^{2+}$ channels were selectively upregulated in the basolateral amygdala neurons, and enhancement of P-type currents could contribute to presynaptic form of LTP.

Key words: isoproterenol; calcium channel; synaptic transmission; long-term potentiation; amygdala; cAMP

$\omega$-agatoxin-IVA ( $\omega$-AgTX), suggesting that enhancement of presynaptic P-type $\mathrm{Ca}^{2+}$ currents may underlie the action of Iso. Because the presynaptic terminals are small and difficult to record from, in the present study we used whole-cell patch-clamp recording techniques in acutely dissociated amygdalar neurons to directly examine the effects of Iso and forskolin on the $\mathrm{Ca}^{2+}$ currents.

\section{MATERIALS AND METHODS}

Slice preparation and intracellular recordings. Male Sprague Dawley rats (125-150 gm) were decapitated, and transverse slices $(500 \mu \mathrm{m})$ were cut from tissue block of the brain using a Vibroslice (Campden Instruments, Silbey, UK). The slices were placed in a beaker of artificial CSF (ACSF) oxygenated with $95 \% \mathrm{O}_{2}-5 \% \mathrm{CO}_{2}$ and kept at room temperature for at least $1 \mathrm{hr}$ before recording. ACSF solution had the following composition (in $\mathrm{mm}$ ): $\mathrm{NaCl} 117, \mathrm{KCl} 4.7, \mathrm{CaCl}_{2} 2.5, \mathrm{MgCl}_{2} 1.2, \mathrm{NaHCO}_{3} 25$, $\mathrm{NaH}_{2} \mathrm{PO}_{4}$ 1.2, and glucose 11 .

A single slice then was transferred to the recording chamber, in which it was held submerged between two nylon nets and maintained at $32 \pm$ $1^{\circ} \mathrm{C}$. The chamber consisted of a circular well of low volume $(1-2 \mathrm{ml})$ and was perfused constantly at a rate of $2-3 \mathrm{ml} / \mathrm{min}$. A bipolar stimulating electrode (SNE-200X; Kopf Instruments, Bern, Germany) was placed in the ventral endopyriform nucleus, near the recording electrode (1-2.5 $\mathrm{mm}$ apart). Orthodromic stimuli were delivered with monophasic constant-voltage pulses at $0.033 \mathrm{~Hz}$ from a Grass stimulator with an isolation unit.

Intracellular recording microelectrodes were pulled from $1.0 \mathrm{~mm}$ microfiber capillary tubing on a Brown-Flaming electrode puller (Sutter Instruments, San Rafael, CA). The electrodes were filled with $4 \mathrm{M}$ potassium acetate with resistance ranging from 60 to $120 \mathrm{M} \Omega$. The microelectrode tips were positioned into the basolateral subdivision of the amygdala. Electrical signals were amplified by using an Axoclamp-2A amplifier (Axon Instruments, Foster City, CA) and recorded on a Gould 3200 chart recorder. For data acquisition and analysis, pClamp 6.0 running on a 486 personal computer was used. All data are expressed as mean \pm SE. Statistical analysis was performed using Student's $t$ test, and $p<0.05$ was considered statistically significant.

Preparation of isolated amygdalar neurons and whole-cell recording$s$. Amygdalar neurons were isolated using a technique adapted from Kay and Wong (1986). Male Sprague Dawley rats aged 2-3 weeks were 

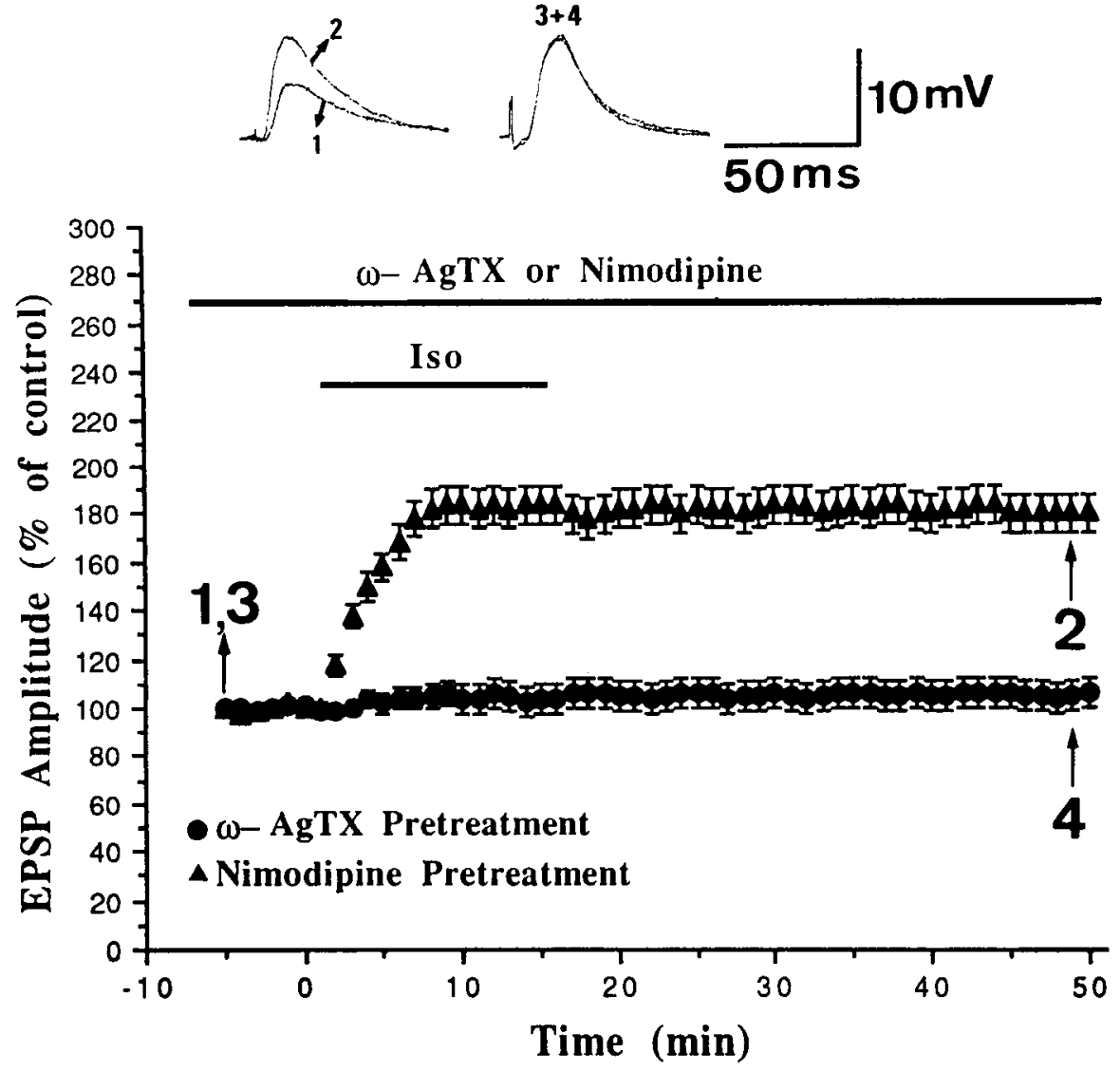

Figure 1. Inhibition of Iso-induced synaptic potentiation by P-type $\mathrm{Ca}^{2+}$ channel blockers. The EPSP amplitude was plotted against time. Bars denote periods of application of Iso $(15 \mu \mathrm{M})$, $\omega$-AgTX $(10 \mathrm{nM})$, or nimodipine $(1 \mu \mathrm{M})$. The slices were incubated in $10 \mathrm{~nm} \omega$-AgTX or $1 \mu \mathrm{M}$ nimodipine for at least $30 \mathrm{~min}$ before being transferred to the recording chamber where the drug was present at the same concentration. decapitated, and serial transverse slices were cut. Amygdalar regions were dissected under a dissection microscope and then transferred to 10 $\mathrm{ml}$ of 1,4-piperazinethanesulfonic acid (PIPES) saline solution in a spinner flask. The temperature was maintained at $32 \pm 1^{\circ} \mathrm{C}$, and $2-3 \mathrm{mg}$ of protease XIV (Sigma, St. Louis, MO) was added. The amygdalar minislices were stirred gently at a rate sufficient to prevent them from settling, and the solution was bubbled continuously with $95 \% \mathrm{O}_{2}-5 \%$ $\mathrm{CO}_{2}$. The PIPES saline solution contained (in $\mathrm{mM}$ ): $\mathrm{NaCl} 120, \mathrm{KCl} 5$, $\mathrm{CaCl}_{2} 1, \mathrm{MgCl}_{2}$ 1, glucose 25, and PIPES 20, $\mathrm{pH}$ 7.0.

One hour later, slices were washed with $10 \mathrm{ml}$ of PIPES saline solution (three times) and transferred for storage to a holding chamber filled with continuously bubbled PIPES saline solution at room temperature. When needed, a slice was transferred to $1 \mathrm{ml}$ of external solution, and the neurons were dissociated by trituration using a fire-polished Pasteur pipette with an $\sim 1 \mathrm{~mm}$ tip diameter. The suspension of dissociated amygdalar neurons then was transferred to a $0.5-1 \mathrm{ml}$ recording chamber mounted on an Olympus IMT-2 inverted microscope. Neurons were allowed to settle on poly-L-lysine-coated coverslips.

Whole-cell $\mathrm{Ca}^{2+}$ currents were recorded using a patch-clamp amplifier (EPC-7, List Electronic) and filtered at $10 \mathrm{KHz}$. Patch pipettes were pulled from borosilicate glass and fire-polished with a resistance of 2-5 $\mathrm{M} \Omega$. The external solution contained (in $\mathrm{mm}$ ): $\mathrm{CaCl}_{2}$ 3, glucose 10 , tetraethylammonium hydrochloride (TEA) 120, 4-aminopyridine (4-AP) 5, and PIPES 10; $2 \mu \mathrm{M}$ tetrodotoxin was always added. Pipette solution contained (in mM): $\mathrm{MgCl}_{2}$ 2, PIPES 10, glucose 10, TEA 20, cesium methanesulfonate 100, EGTA 10, Mg-ATP 4, Na-GTP 0.3, phosphocreatine 20, and leupeptin 0.2 .

\section{RESULTS}

To confirm the involvement of P-type $\mathrm{Ca}^{2+}$ channel in the action of Iso, we investigated the effect of $\omega$-AgTX on Iso-induced potentiation. Slices were incubated in $10 \mathrm{~nm} \omega$-AgTX for at least 30 min before being transferred to the recording chamber where the drug was present at the same concentration. Figure 1 shows that Iso no longer induced LTP in slices pretreated with $\omega$-AgTX (103 $\pm 10 \%, n=8)$. In contrast, the EPSP amplitude was increased to $183 \pm 8 \%(n=6)$ by Iso in slices pretreated with 1 $\mu \mathrm{M}$ nimodipine (Fig. 1). These results suggest the involvement of P-type currents in the action of Iso.

To determine whether the increase in EPSP was in fact caused by a decrease in IPSP, we examined the effect of Iso on the monosynaptic IPSP. Monosynaptic IPSPs were evoked by focal

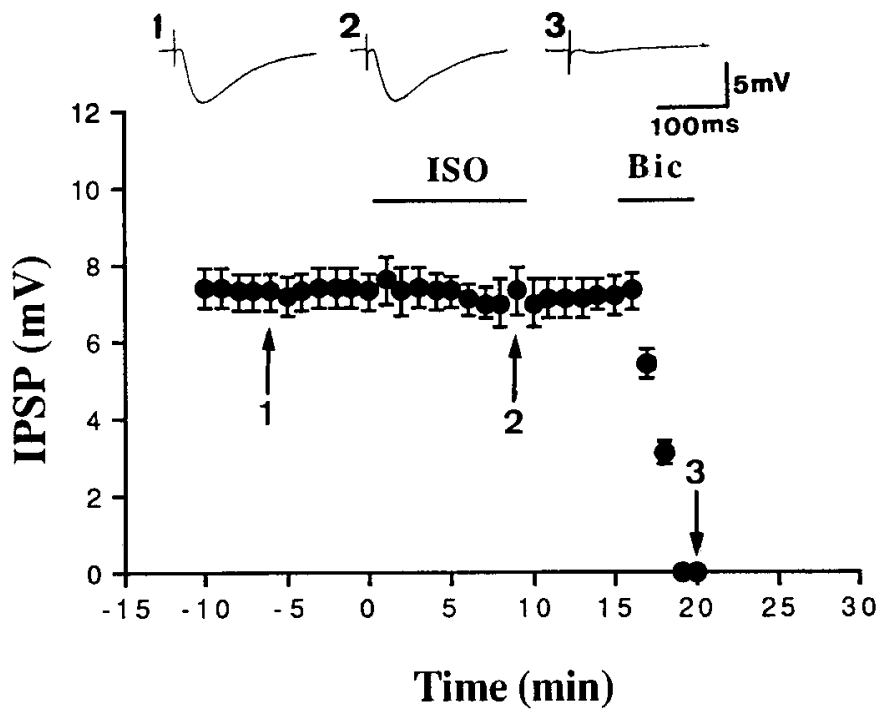

Figure 2. Iso does not affect the IPSP. Monosynaptic IPSP was evoked in the presence of $10 \mu \mathrm{M}$ 6-cyano-7-nitroquinoxaline-2,3-dione and $50 \mu \mathrm{M}$ D-2-amino-5-phosphonovalerate. At the end of experiments, $20 \mu \mathrm{M}$ bicuculline (Bic) was added to confirm that the IPSP was indeed mediated by $\mathrm{GABA}_{\mathrm{A}}$ receptors. 


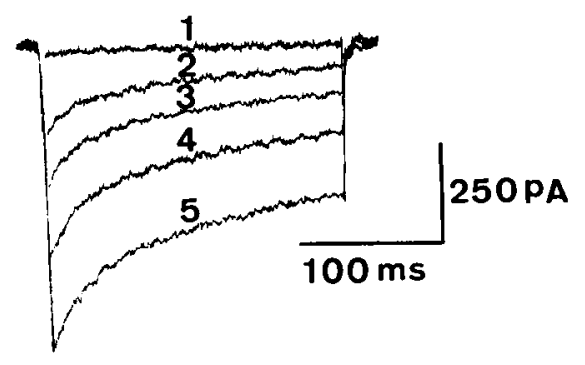

Figure 3. Pharmacological separation of $I_{\mathrm{Ca}}$ in amygdalar neurons. Plot of peak $I_{\mathrm{Ca}}$ versus time is shown for an experiment in which $1 \mu \mathrm{M}$ nimodipine, $1 \mu \mathrm{M}$ nimodipine plus $\omega$-CgTX, $10 \mathrm{~nm}$ nimodipine plus $\omega$-CgTX plus $\omega$-AgTX, and $100 \mu \mathrm{M} \mathrm{Cd}^{++}$were sequentially applied to an amygdala neuron.

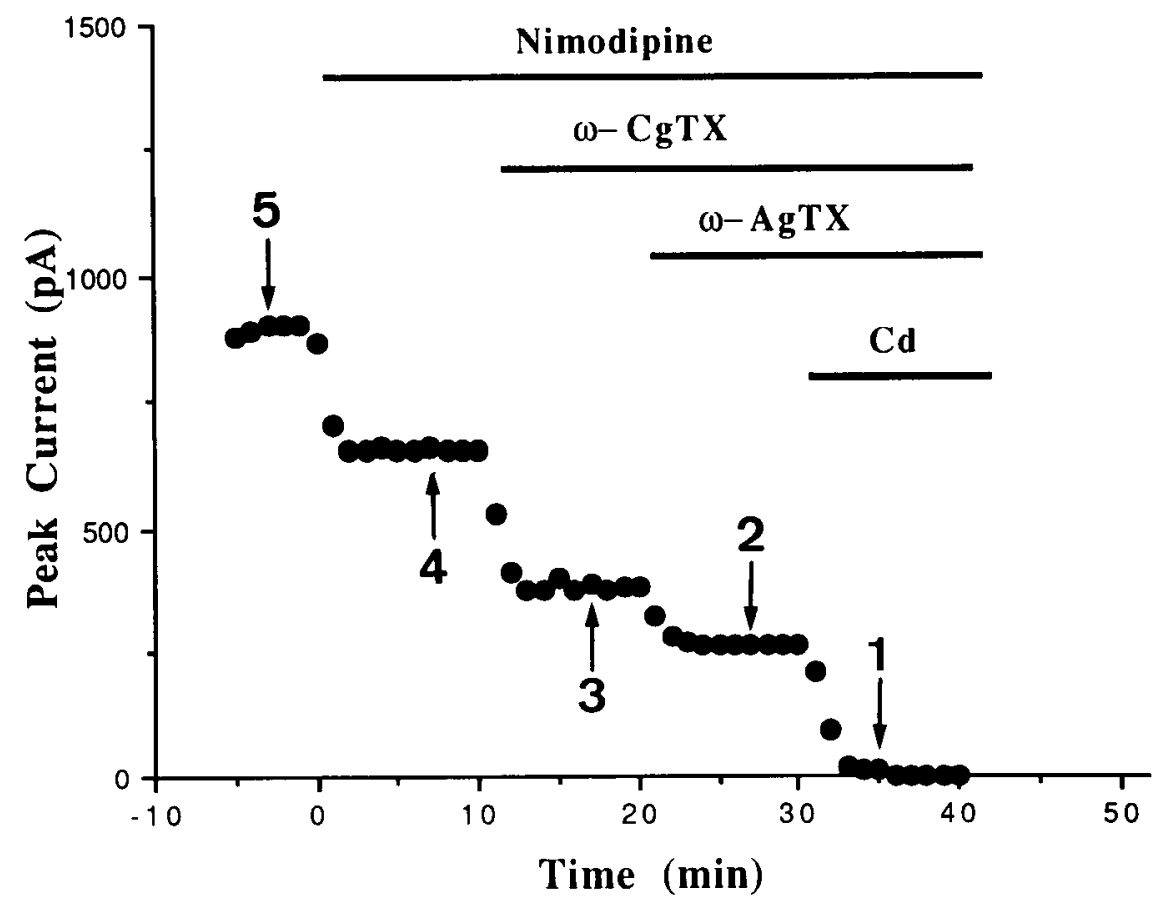

stimulation in the presence of glutamate receptor antagonists: 10 $\mu \mathrm{M}$ 6-cyano-7-nitroquinoxaline-2,3-dione and $50 \mu \mathrm{M}$ D-2-amino5-phosphonovalerate. Depolarization of the membrane potential increased the amplitude of IPSP, whereas hyperpolarization of the membrane potential decreased the amplitude of IPSP. In six neurons, IPSP reversed polarity at $-69 \pm 2 \mathrm{mV}$ (data not shown) (Rainnie et al., 1991). Figure 2 shows that Iso had no effect on the IPSP, in agreement with previous results described by Washburn and Moises (1992).

We tested the effect of Iso on the whole-cell $\mathrm{Ca}^{2+}$ currents $\left(I_{\mathrm{Ca}}\right)$ directly in dissociated amygdalar neurons. A sustained inward $I_{\mathrm{Ca}}$ was normally activated at approximately $-40 \mathrm{mV}$, peaked at $-10 \mathrm{mV}$, and reversed between +30 and $+40 \mathrm{mV}$ (Foehring and Scroggs, 1994; Viana and Hille, 1996; Wang et al., 1996) when elicited by $200 \mathrm{msec}$ step commands from a holding potential of $-70 \mathrm{mV}$. We used pharmacological agents to dissect the $I_{\mathrm{Ca}}$. L-type current was defined as the current blocked by a saturating concentration of $1 \mu \mathrm{M}$ nimodipine. On average, nimodipine blocked $35.0 \pm 4.2 \%(n=9)$ of the whole-cell current. $\mathrm{N}$-type current was defined as the current blocked by $1 \mu \mathrm{M}$ $\omega$-conotoxin-GVIA $(\omega$-CgTX). On average, $29.5 \pm 1.1 \%(n=5)$ of the $I_{\mathrm{Ca}}$ was blocked by $\omega$-CgTX. P-type current was defined as the current blocked by a low concentration of $\omega$-AgTX (10 nM) (Mintz et al., 1992; Randall and Tsien, 1995). On average, $10 \mathrm{~nm}$ $\omega$-AgTX blocked $20.0 \pm 1.3 \%$ of the $I_{\mathrm{Ca}}$, which was consistent with previous results showing a similar degree of $I_{\mathrm{Ca}}$ blockage by this concentration of neurotoxin (Foehring and Scroggs, 1994).

Figure 3 illustrates the effects of nimodipine, nimodipine plus $\omega$-CgTX, and nimodipine plus $\omega$-CgTX plus $\omega$-AgTX in an amgydalar neuron. Nimodipine $(1 \mu \mathrm{M})$ alone blocked $27.6 \%$ of the current, and nimodipine plus $\omega$-CgTX blocked $58 \%$. Simultaneous application of nimodipine plus $\omega$-CgTX plus $\omega$-AgTX blocked $71.3 \%$ of the current, leaving $28.7 \%$ unblocked. The current that remained in the presence of all three antagonists may contain Q- and R-type $\mathrm{Ca}^{2+}$ currents that were subsequently blocked by $100 \mu \mathrm{M} \mathrm{Cd}^{++}$. A similar degree of inhibition was observed in five additional cells.

Figure $4 A$ shows that bath application of $15 \mu \mathrm{M}$ Iso persistently enhanced $I_{\mathrm{Ca}}$. On average, Iso increased the current by $54 \pm 7 \%$ $(n=11 ; p<0.001)$. Iso apparently did not change the kinetics of $I_{\mathrm{Ca}}$; the current at the beginning of a voltage command (the peak current) was enhanced by the same degree as the current at the end of the command. In addition, as can be seen in Figure $4 A$, concurrent application of $1 \mu \mathrm{M}$ propranolol with Iso prevented the effect of Iso $(102 \pm 4 \%, n=6)$, indicating the involvement of $\beta$-adrenergic receptors. Furthermore, to exclude the possibility that the sustained effect was caused by a slow washout of Iso from the slices, we applied propranolol during the washout period. In six neurons, delayed application of $1 \mu \mathrm{M}$ propranolol did not affect the Iso-induced sustained enhancement of $I_{\mathrm{Ca}}$ (Fig. 4B), 


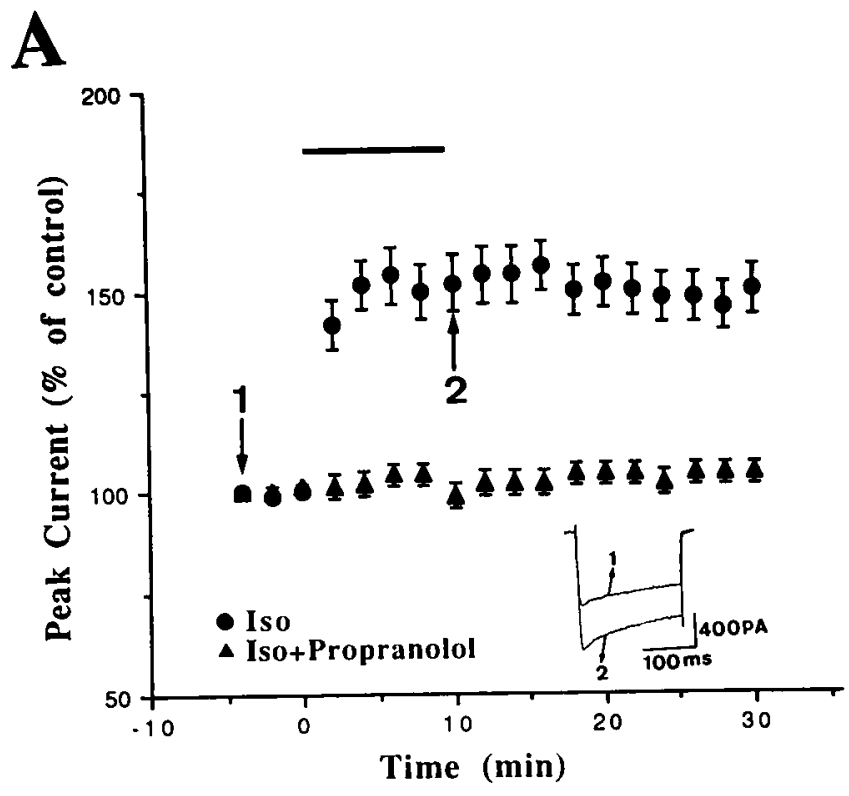

B

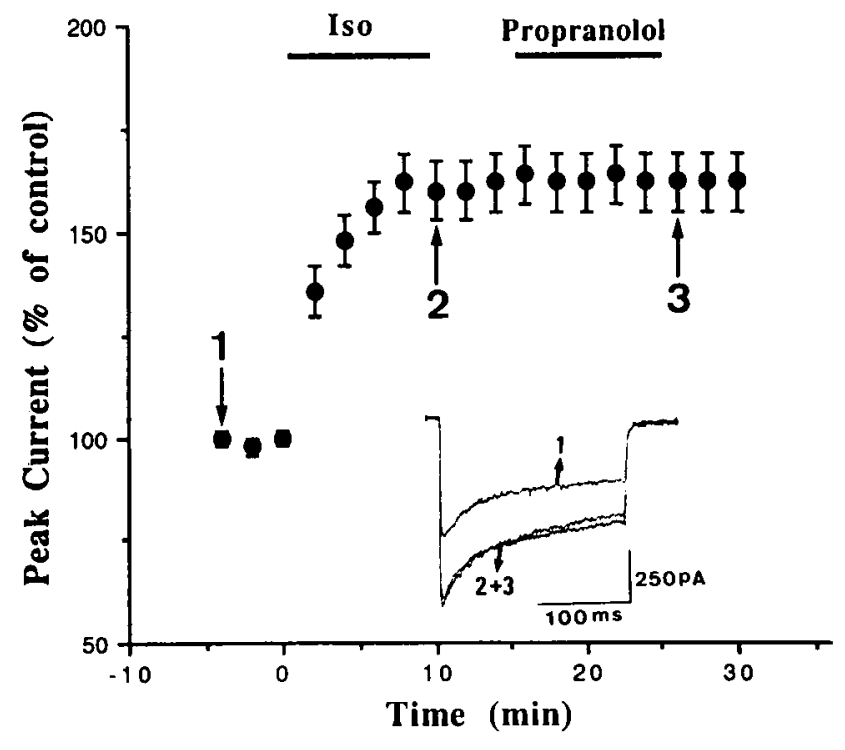

Figure 4. Persistent enhancement of $I_{\mathrm{Ca}}$ by Iso. $A$, The percent change of peak $\mathrm{I}_{\mathrm{Ca}}$ was plotted as a function of time. Bar denotes the periods of delivery of Iso $(15 \mu \mathrm{M})$ or Iso plus propranolol $(1 \mu \mathrm{M})$. The Iso-induced potentiation was prevented by concurrent application of propranolol. $B$, Delayed application of propranolol after $I_{\mathrm{Ca}}$ enhancement did not affect Iso-induced potentiation significantly.

suggesting that the long-term effect was not the result of a continued activation of $\beta$-adrenergic receptors by Iso.

We next examined whether Iso affects a particular type of channel. If the Iso modulation was of N-type channel exclusively, then no modulation should be evident in the presence of $1 \mu \mathrm{M}$ $\omega$-CgTX. However, this is not the case. In six cells pretreated with $\omega$-CgTX, Iso increased the current by $68 \pm 4 \%$ (Fig. $5 A$ ). The same experimental design was performed by using $1 \mu \mathrm{M}$ L-type blocker nimodipine. As illustrated in Figure $5 B$, Iso increased the current by $58 \pm 10 \%(n=6)$ in the presence of nimodipine. These data suggest that $\mathrm{N}$ - and L-type channels are not involved in the modulation by Iso. We next tested the hypoth-
$\mathbf{A}$
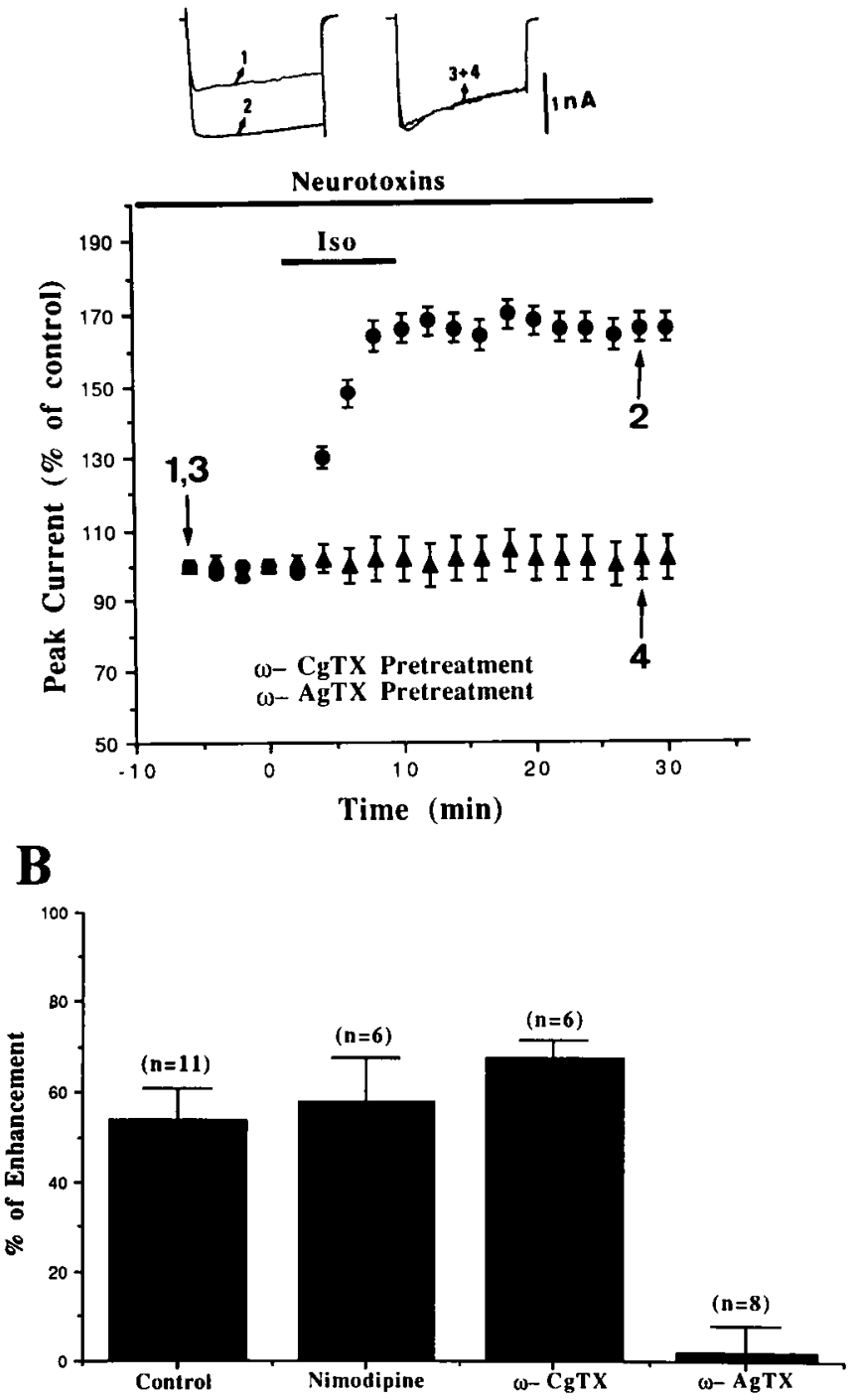

Figure 5. Selective blockade of Iso-induced enhancement of $I_{\mathrm{Ca}}$ by $\omega$-AgTX. $A$, The percent change of $I_{\mathrm{Ca}}$ was plotted as a function of time. The isolated amygdalar neurons were incubated in $1 \mu \mathrm{M} \omega$-CgTX or 10 $\mathrm{nm} \omega$-AgTX for at least 10 min before recordings were made. $B$, The bars represent the enhancement of $I_{\mathrm{Ca}}$ (mean $\pm \mathrm{SEM}$ ) by Iso in control and after application of various types of $\mathrm{Ca}^{2+}$ channel blockers.

esis that P-type channels were modulated by Iso. Figure $5 A$ clearly shows that the effect of Iso was completely eliminated by $10 \mathrm{~nm} \omega$-AgTX. The current remained $102 \pm 6 \%(n=8)$ of its baseline.

If activation of $\beta$-adrenergic receptors enhanced $I_{\mathrm{Ca}}$ via PKA activation, then a direct activator of adenylyl cyclase should mimic the effect of Iso. Figure $6 A$ shows that bath application of $25 \mu \mathrm{M}$ forskolin produced an effect similar to that of Iso. On average, $I_{\mathrm{Ca}}$ was increased by $38 \pm 6 \%(n=5)$. Rp-adenosine 3',5'-cyclic monophosphothioate (Rp-cAMPS), a membranepermeable PKA inhibitor, effectively blocked forskolin-induced enhancement of $I_{\mathrm{Ca}}$. In the presence of $25 \mu \mathrm{M}$ Rp-cAMPS, the $\mathrm{I}_{\mathrm{Ca}}$ remained $101 \pm 1 \%$ of baseline $(n=6$; Fig. $6 \mathrm{~B})$. Pretreatment of cells with $\omega$-AgTX similarly abolished the effect of forskolin (100 $\pm 6 \%$ of control; $n=6$; Fig. $6 A)$.

TEA at a concentration that blocks the delayed rectifier $\mathrm{K}^{+}$ 

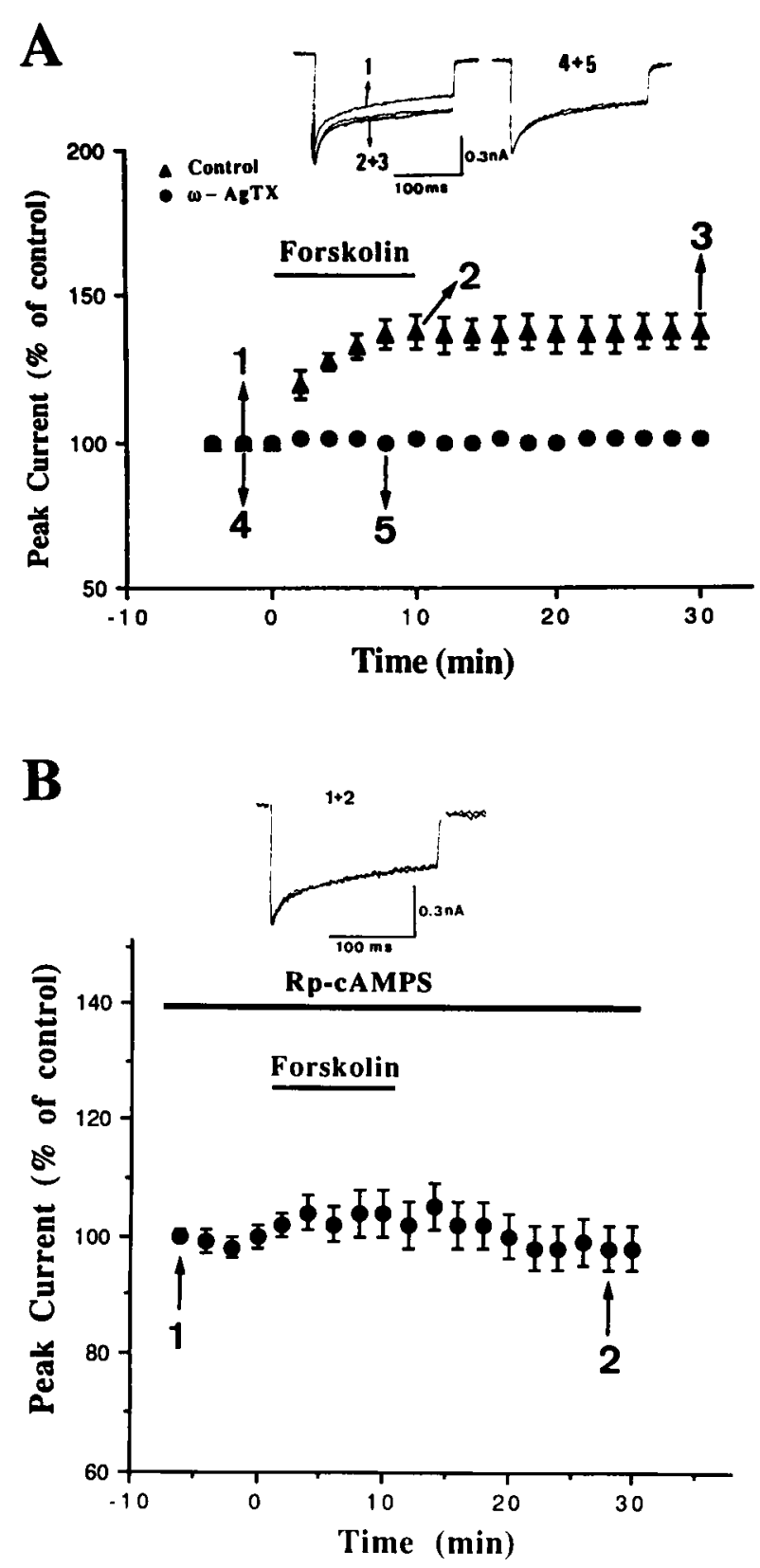

Figure 6. Sustained enhancement of $I_{\mathrm{Ca}}$ by forskolin and its inhibition by $\omega$-AgTX and Rp-cAMPS. $A$, The percent change of peak $I_{\mathrm{Ca}}$ was plotted as a function of time. Bar denotes the period of application of $25 \mu \mathrm{M}$ forskolin. In $10 \mathrm{nM} \omega$-AgTX-treated neurons, the neurotoxin was present for at least $10 \mathrm{~min}$ before and during the period of recording. $B$, The effect of forskolin was abolished by Rp-cAMPS. The isolated neurons were incubated with $25 \mu \mathrm{M}$ Rp-cAMPS for at least $20 \mathrm{~min}$ before and during the period of recording.

channels has been shown to produce a long-lasting enhancement of synaptic transmission (Aniksztejn and Ben-Ari, 1991; Huang and Malenka, 1993; Hanse and Gustafsson, 1994). Therefore, the delayed rectifier $\mathrm{K}^{+}$channels could be a possible target for modulation. The delayed rectifier $\mathrm{K}^{+}$currents were elicited by depolarization from a holding potential of -70 to $+60 \mathrm{mV}$ in the presence of $100 \mu \mathrm{M} \mathrm{Cd}^{++}$and $5 \mathrm{~mm} 4-\mathrm{AP}$. This $\mathrm{K}^{+}$current was activated on depolarization positive to $-50 \mathrm{mV}$, and its magnitude increased on further depolarization. In all six cells tested, Iso had no affect on the delayed rectifier $\mathrm{K}^{+}$currents (Fig. 7).

\section{DISCUSSION}

In many excitatory synapses, activation of the PKA pathway has been shown to increase transmitter release, persistently or reversibly, depending on the preparations studied. In hippocampal mossy fiber $\rightarrow$ CA3 synapses (Huang et al., 1994; Weisskopf et al., 1994), cerebellar parallel fiber synapses (Salin et al., 1996), and basolateral amygdala neurons (Huang et al., 1996), an increase in cAMP and activation of PKA resulted in a persistent facilitation of transmitter release, a phenomenon that may have contributed to a presynaptic form of LTP. In contrast, in Schaffer collateral $\rightarrow$ CA1 synapses, transmitter release was enhanced in a reversible manner (Chavez-Noriega and Stevens, 1992; Gereau and Conn, 1994). Thus, it is likely that the excitation-secretion coupling processes are differentially regulated by PKA in different brain areas.

Voltage-dependent $\mathrm{Ca}^{2+}$ channels are unique in neuronal communication in terms of transduction of an electrical signal (membrane depolarization) via $\mathrm{Ca}^{2+}$ entry into a chemical signal (neurotransmitter release) (Llinas et al., 1981). Theoretically, modification of $\mathrm{Ca}^{2+}$ channels could be an effective means of regulating neurotransmission. However, it is suggested that reversible enhancement of glutamate release by forskolin in cultured hippocampal neurons was not attributable to an alteration in depolarization-evoked increase in intracellular $\mathrm{Ca}^{2+}$ but was accompanied by a direct modulation of secretory machinery downstream from $\mathrm{Ca}^{2+}$ influx (Trudeau et al., 1996). It is not known whether the same mechanism underlies PKA-induced long-term enhancement of glutamate release in other synapses.

In the present study, we have demonstrated that activation of $\beta$-adrenergic receptor and the enzyme adenylyl cyclase persistently increased the whole-cell $\mathrm{Ca}^{2+}$ currents that paralleled a long-term enhancement of transmitter release. Both effects were blocked by the P-type $\mathrm{Ca}^{2+}$ channel blocker $\omega$-AgTX but not by L- or N-type blockers. These results indicate that both presynaptic and postsynaptic P-type $\mathrm{Ca}^{2+}$ channels are subject to neuromodulation by PKA, and that long-term enhancement of $\mathrm{Ca}^{2+}$ currents may underlie the Iso-induced presynaptic form of LTP in the amygdala. However, unless presynaptic $\mathrm{Ca}^{2+}$ currents and PSPs could be recorded simultaneously in the basolateral amygdala, it is difficult to prove directly any causal relationship between P-type channel modulation and synaptic potentiation. Therefore, we cannot exclude the possibility that the enhancement of transmission may involve additional mechanisms such as a direct modulation of secretory machinery downstream from $\mathrm{Ca}^{2+}$ influx (Trudeau et al., 1996).

The mechanisms involved in Iso potentiation of P-type $\mathrm{Ca}^{2+}$ channels in amygdalar neurons remain to be determined. Phosphorylation by PKA modulates voltage-dependent $\mathrm{Ca}^{2+}$ channels in several excitable cells (Dolphin, 1996). The modulation of L-type $\mathrm{Ca}^{2+}$ channels has been repeatedly demonstrated in the central neurons (Gray and Johnston, 1987; Kavalali et al., 1997). Only in two studies, one in hippocampal CA3 neurons and the other in Xenopus oocytes expressed with human $\beta$ subunits, was selective enhancement of P-type currents via stimulation of adenylyl cyclase reported (Mogul et al., 1993; Fukuda et al., 1996), although the reversibility of the drug effect was not addressed. In the present study, we found that the increase in $I_{\mathrm{Ca}}$ outlasted the duration of application of Iso and administration of propranolol before but not after $I_{\mathrm{Ca}}$ enhancement prevented the effect of Iso. These results suggest that the long-term effect was not attributable to a slow washout of Iso. In the future, it would be of interest 


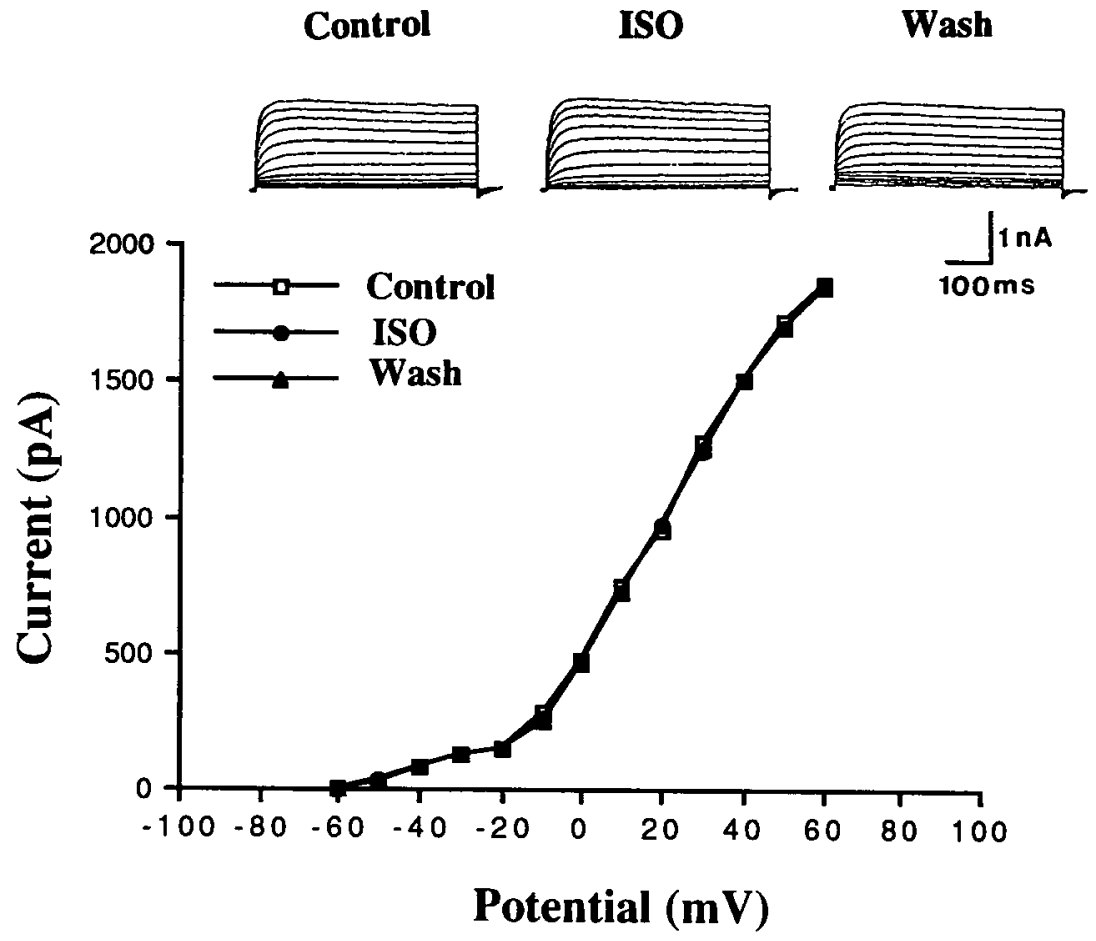

Figure 7. Iso does not affect the delayed rectifier $\mathrm{K}^{+}$ currents. Delayed rectifier $\mathrm{K}^{+}$currents were elicited by depolarizing pulses over the potential ranges of -60 to $+60 \mathrm{mV}$ from a holding potential of $-70 \mathrm{mV}$ in the presence of $100 \mu \mathrm{M} \mathrm{Cd}^{++}$and $5 \mathrm{~mm}$ 4-aminopyridine. to determine whether long-term effect was caused by a continued kinase activity by delayed application of Rp-cAMPS or inhibitors of the PKA catalytic site.

In light of the significant contribution of P-type channels to presynaptic $\mathrm{Ca}^{2+}$ entry and transmitter release (Luebke et al., 1993; Takahashi and Momiyama, 1993; Wheeler et al., 1994), persistent enhancement of these channels will have a profound influence on neuronal activity in the amygdala. Indeed, behavioral studies have shown that post-training intra-amygdala administration of $\beta$-adrenergic agonists enhances the retention of an inhibitory avoidance task (Liang et al., 1986). More importantly, in normal humans, propranolol, a $\beta$-adrenergic blocker, selectively impaired long-term memory for an emotionally arousing short story (Cahill et al., 1994). In addition, the patient with bilateral brain damage confined to the amygdala failed to show normal memory associated with emotional arousal (Cahill et al., 1995).

\section{REFERENCES}

Aniksztejn L, Ben-Ari Y (1991) Novel form of long-term potentiation produced by a $\mathrm{K}^{+}$channel blocker in the hippocampus. Nature 349:67-69.

Bliss TVP, Collingridge GL (1993) A synaptic model of memory: longterm potentiation in the hippocampus. Nature 361:31-39.

Bliss TVP, Lomo T (1973) Long-lasting potentiation of synaptic transmission in the dentate area of the anaesthetized rabbit following stimulation of the perforant path. J Physiol (Lond) 232:331-356.

Blitzer RD, Wong T, Nouranifar R, Lyengar R, Landau EM (1995) Postsynaptic cAMP pathway gates early LTP in hippocampal CA1 region. Neuron 15:1403-1414.

Byrne JH, Kandel ER (1996) Presynaptic facilitation revisited: state and time dependence. J Neurosci 16:425-435.

Cahill L, Prins B, Weber M, McGaugh JL (1994) $\beta$-adrenergic activation and memory for emotional events. Nature 371:702-704.

Cahill L, Babinsky R, Markowitsch HJ, McGaugh JL (1995) The amygdala and emotional memory. Nature 377:295-296.

Chavez-Noriega LE, Stevens CF (1992) Modulation of synaptic efficacy in field CA1 of the rat hippocampus by forskolin. Brain Res 574:85-92.
Dolphin AC (1996) Facilitation of $\mathrm{Ca}^{++}$current in excitatory cells. Trends Neurosci 19:35-43.

Foehring RC, Scroggs RS (1994) Multiple high-threshold calcium currents in acutely isolated rat amygdaloid pyramidal cells. J Neurophysiol 71:433-436.

Fukuda K, Kaneko S, Yada N, Kikuwaka M, Akaike A, Satoh M (1996) Cyclic AMP-dependent modulation of $\mathrm{N}$ - and Q-type $\mathrm{Ca}^{++}$channels expressed in Xenopus oocytes. Neurosci Lett 217:13-16.

Gereau RW, Conn PJ (1994) Presynaptic enhancement of excitatory synaptic transmission by $\beta$-adrenergic receptor activation. J Neurophysiol 72:1438-1442.

Gray R, Johnston D (1987) Noradrenaline and $\beta$-adrenoreceptor agonists increase activity of voltage-dependent calcium channels in hippocampal neurons. Nature 327:620-622.

Hanse E, Gustafsson B (1994) TEA elicits two distinct potentiations of synaptic transmission in the CA1 region of the hippocampal slices. J Neurosci 14:5028-5034.

Huang Y-Y, Malenka RC (1993) Examination of TEA-induced synaptic enhancement in area CA1 of the hippocampus: the role of voltagedependent $\mathrm{Ca}^{++}$channels in the induction of LTP. J Neurosci 13:568-576.

Huang Y-Y, Li X-C, Kandel ER (1994) cAMP contributes to mossy fiber LTP by initiating both a covalent-mediated early phase and macromolecular synthesis-dependent late phase. Cell 79:69-79.

Huang CC, Hsu KS, Gean PW (1996) Isoproterenol potentiates synaptic transmission primarily by enhancing presynaptic calcium influx via Pand/or Q-type calcium channels in the rat amygdala. J Neurosci 16:1026-1033.

Kavalali ET, Hwang KS, Plummer MR (1997) cAMP-dependent enhancement of dihydropyridine-sensitive calcium channel availability in hippocampal neurons. J Neurosci 15:5334-5348.

Kay AR, Wong RKS (1986) Isolation of neurons suitable for patchclamping from adult mammalian central nervous system. J Neurosci Methods 16:227-238

Levitan IB (1985) Phosphorylation of ion channels. J Membr Biol 87:177-190.

Liang KC, Juler RG, McGaugh JL (1986) Modulating effects of posttraining epinephrine on memory: involvement of the amygdala noradrenergic system. Brain Res 368:125-133.

Llinas R, Steinberg IZ, Walton K (1981) Presynaptic calcium currents in squid giant synapse. Biophys J 33:289-322.

Luebke JI, Dunlap K, Turner TJ (1993) Multiple calcium channel types 
control glutamatergic synaptic transmission in the hippocampus. Neuron 11:895-902.

Mintz IM, Venema VJ, Swiderek KM, Lee TD, Bean BP, Adams ME (1992) P-type calcium channels blocked by the spider toxin $\omega$-AgaIVA. Nature 355:827-829.

Mogul DJ, Adams ME, Fox AP (1993) Differential activation of adenosine receptors decreases $\mathrm{N}$-type but potentiates $\mathrm{P}$-type $\mathrm{Ca}^{++}$current in hippocampal CA3 neurons. Neuron 10:327-334.

Nestler EJ, Greengard P (1984) Protein phosphorylation in the nervous system. New York: Wiley.

Rainnie DG, Asprodini EK, Shinnick-Gallagher P (1991) Inhibitory transmission in the basolateral amygdala. J Neurophysiol 66:999-1009.

Randall A, Tsien RW (1995) Pharmacological dissection of multiple types of $\mathrm{Ca}^{++}$channel currents in rat cerebellar granule neurons. J Neurosci 15:2995-3012.

Salin PA, Malenka RC, Nicoll RA (1996) Cyclic AMP mediates a presynaptic form of LTP at cerebellar parallel fiber synapses. Neuron 16:797-803.

Takahashi T, Momiyama A (1993) Different types of calcium channels mediate central synaptic transmission. Nature 366:156-158.
Thomas MJ, Moody TD, Makhinson M, O’Dell TJ (1996) Activitydependent $\beta$-adrenergic modulation of low frequency stimulation induced LTP in the hippocampal CA1 region. Neuron 17:475-482.

Trudeau LE, Emery DG, Haydon PG (1996) Direct modulation of the secretory machinery underlies PKA-dependent synaptic facilitation in hippocampal neurons. Neuron 17:789-797.

Viana F, Hille B (1996) Modulation of high voltage-activated calcium channels by somatostatin in acutely isolated rat amygdaloid neurons. J Neurosci 16:6000-6011.

Wang SJ, Huang CC, Hsu KS, Tsai JJ, Gean PW (1996) Inhibition of N-type calcium currents by lamotrigine in rat amygdalar neurones. NeuroReport 7:3037-3040.

Washburn MS, Moises HC (1992) Inhibitory responses of rat basolateral amygdaloid neurons recorded in vitro. Neuroscience 50:811-830.

Weisskopf MG, Castillo PE, Zalutsky RA, Nicoll RA (1994) Mediation of hippocampal mossy fiber long-term potentiation by cyclic AMP. Science 265:1878-1882.

Wheeler DB, Randall A, Tsien RW (1994) Roles of N-type and Q-type $\mathrm{Ca}^{++}$channels in supporting hippocampal synaptic transmission. Science 264:107-111. 